\title{
Análisis Rítmico de "Oda con un Lamento"
}

El método que me he propuesto en este análisis es básicamente formal -en razón misma del nivel elegido para comentar el poema-, pero también interpretativo. $Y$ esto último en dos direcciones, que no se excluyen necesariamente: la que conecta con la tradición formalista rusa tanto como con la de investigadores anglosajones, explotadas tan brillantemente hasta nuestros días por Roman Jakobson ${ }^{1}$ (criterio estructural de conexión interna de planos: las afinidades rítmico-sonoras sugieren o refuerzan afinidades semánticas); y el criterio clásico del ritmo como procedimiento 'imitativo', que no murió con los estudios de Grammont ${ }^{2}$ y no hace mucho ha vuelto a defender Ivan Fónagy con convincente ob. jetividad de pruebas. ${ }^{3}$ El concepto básico de ritmo con que me voy a manejar, entendido como una relación - no necesariamente repetitivade tensión/distensión, coincide fundamentalmente con el que planteó en su momento Amado Alonso; ${ }^{4}$ y según he adelantado en parte, no se agota con la consideración de los aspectos métricos de un poema, ya que aquí lo métrico se maneja integradoramente en su relación —unas veces con-

1 Vid. R. Jakobson, "Linguistics and Poetics", en T. A. Sebeok (ed.), Style in language, Cambridge, Mass., 1960, 350-77. Y en versión francesa: R. Jakobson, Essais de linguistique générale, Paris, 1963, 209-48, cap. "Poétique". Sin embargo, el sesgo metodológico aplicado por este investigador en colaboración con C. LéviStrauss en su estudio "Les chats de Charles Baudelaire" (L'Homme, II, No. 1, 1962), mereció un reparo fundamental por parte de $M$. Riffaterre, que me parece atendible desde la perspectiva de una consideración estilística de los textos: no son estilisticamente pertinentes las relaciones que, por conectar apariciones demasiado distantes entre sí, son imposibles de percibir en el orden de sucesividad que impone una lectura normal: vid. M. Riffaterre, "Describing poetic structures: two approaches to Baudelaire's Les Chats" (en Yale French Studies, vol. Structuralism, oct. 1966, 200-42).

2 Me remito a la obra clásica de M. Grammont Le vers français, Paris, 1937.

3 I. Fónagy, "Le langage poétique: forme et fonction", en el vol. colectivo Problèmes du langage, col. Diogène, Paris, 1966, 72-116.

4 A. Alonso, "El ritmo de la prosa" y "La musicalidad de la prosa en ValleInclán", en su Materia y forma en poesia, Madrid, 1955, 301-12 y 313-69 respectivamente. 
dicionante, otras condicionada - con el resto de los materiales poéticos; éstos, claro está, sólo en cuanto se ordenan para configurar el díseño ritmico total de la obra, que debemos concebir como la resultante de una combinatoria cuyos ingredientes son: los modelos de verso seleccionados por aquélla, más el 'impulso rítmico', o 'dominante' a que da lugar el margen de libertad de esos modelos de verso, más todo material semántico, morfo-sintáctico, léxico y aun de contenidos no estrictamente lingüisticos que sean relevantes para constituir la figura rítmica peculiar de la obra. Y como mi propósito no es caracterizar el lenguaje poético de estos versos en cuanto versal-poético sino en cuanto rítmico (también existen realizaciones de ritmo en la prosa), no me he atenido al método - por otra parte excelente por su coherencia y fecundidad de resultados- practicado por Samuel Levin y Nicolas Ruwet, ${ }^{5}$ en su intento por delimitar el nivel de pertinencia del lenguaje en verso - que es un nivel rítmico, con toda evidencia-: atenerse a él implicaría desatender elementos de expresión relevantes desde mi punto de vista, aun cuando ellos no entren en la legalidad del 'lenguaje poético en verso'. Por otra parte, el método Levin-Ruwet es altamente eficaz mientras se lo aplique a un tipo de versificación regular-convencional, ya que uno de los elementos con que tra. baja para detectar sus 'couplings' o 'couplages' son los modelos convenidos de verso en una tradición cultural, esquemas fijos de rimas, etc., a que se somete la obra analizada; pero en la oda de Pablo Neruda que nos ocupa, la utilización de normas métricas fijas es muy parcial, y su estructura métrica semilibre ofrece, como los poemas en verso totalmente libre, posibilidades propias de efectos locales aislados, como también de ritmo interestrófico y formas especiales de destaque, que reclaman un método apropiado para ser cabalmente descriptas. En el estudio que dedicó Ama. do Alonso a Residencia en la tierra se tocan esos aspectos precisamente en función de este poemario, y ocasionalmente, de nuestro poema: ${ }^{6}$ pues

5 S. Levin, Linguistic Structures in Poetry, La Haya, 1962. N. Ruwet, "L'analyse structurale de la poésie" (Linguistics, II, 1963, 38-59).

6 A. Alonso, Poesía y estilo de Pablo Neruda, Bs. Aires, 2a., 1951 (espec. cap. IV). Aquí damos por conocida la interpretación que de los símbolos nerudianos ofrece ese autor. Más allá de los manuales de versificación corriente (Navarro Tomás, Baehr, Balbín Lucas), en el ámbito hispánico of rece una puesta al dia del problema del versolibrismo la obra de F. López Estrada Métrica española del siglo XX, Madrid, 1969: aunque no siempre comparto su modo de relacionar la 'línea' fluctuante de los poemas que analiza, con modelos de verso o de pies métricos susceptibles de rastrear en esas líneas, pues para detectarlos es preciso a veces forzar la lectura espontánea del texto con hiatos no esperables en una versificación no regular; es el mismo equívoco en que incurre $N$. Baquero Goyanes al estudiar los metricismos en la prosa de Azorín (vid. su Prosistas españoles contemporáneos, Madrid, 1956, 253-84). Sin salirnos de la literatura en español, el vol. colectivo Elementos formales en la lívica actual, Santander, 1967, contine 
en una versificación total o parcialmente liberada de patrones métricos, el margen de imprevisibilidad a que eso da lugar permite al poema consti. tuir su propia legalidad rítmica con recursos vedados a la versificación regular. ${ }^{3}$

algunos artículos que hacen a nuestro tema (Alarcos Llorach, E. de Frutos, F. López Estrada, J. A. Rey, L. Rodríguez Alcalde), aunque no siempre colman la expectativa que en un principio despiertan.

7 Anticipo aquí el texto del poema:

\section{ODA CON UN LAMENTO}

I. Oh niña entre las rosas, oh presión de palomas, oh presidio de peces y rosales,

tu alma es una botella llena de sal sedienta y una campana llena de uvas es tu piel.

II. Por desgracia no tengo para darte sino uñas o pestañas, o pianos derretidos, o sueños que salen de mi corazón a borbotones, polvorientos sueños que corren como jinetes negros, sueños llenos de velocidades $y$ desgracias.

III. Sólo puedo quererte con besos y amapolas, con guirnaldas mojadias por la lluvia, mirando cenicientos caballos y perros amarillos.

Sólo puedo quererte con olas a la espalda, entre vagos golpes de azufre y aguas ensimismadas,

nadando en contra de los cementerios que corren en ciertos ríos con pasto mojado creciendo sobre las tristes tumbas de yeso, nadando a través de corazones sumergidos y pálidas planillas de niños insepultos.

IV. Hay mucha muerte, muchos acontecimientos funeratios en mis desamparadas pasiones y desolados besos, hay el agua que cae en mi cabeza, mientras crece mi pelo, un agua como el tiempo, un agua negra desencadenada, con una voz nocturna, con un grito

de pájaro en la lluvia, con una interminable sombra de ala mojada que protege mis huesos: mientras me visto, mientras interminablemente me miro en los espejos y en los vidrios, oigo que alguien me sigue llamándome a sollozos con una triste voz podrida por el tiempo.

V. Tú estás de pie sobre la tierra, llena de dientes y relámpagos.

Tú propagas los besos y matas las hormigas.

Tú lloras de salud, de cebolla, de abeja, de abecedario ardiendo. Tú eres como una espada azul y verde $y$ ondulas al tocarte, como un río.

VI. Ven a mi alma vestida de blanco, con un ramo de ensangrentadas rosas y copas de cenizas, ven con una manzana y un caballo, porque allí hay una sala oscura y un candelabro roto, unas sillas torcidas que esperan el invierno, y una paloma muerta, con un número. 
Ya a nivel de los contenidos estróficos es significativa la distribución de los temas estructurantes del poema, dos de los cuales constituyen un ritmo alternante ( $A=$ la Amada; $P=$ el Poeta amante), mientras el tercero ( $M=$ caos amenazante del Mundo) va explicitándose progresivamente a partir de la segunda estrofa y siempre sobrepuesto a cada uno de los otros dos:

$$
\begin{aligned}
& \text { E. I }(4 \text { vsos. }) \ldots \text { Amada } \\
& \text { E. II }(5 \text { vsos. }) \ldots . \text { Poeta } \\
& \text { E. III }(9 \text { vsos. } \ldots .\} \text { (y } \\
& \text { E. IV }(12 \text { vsos. } \ldots .\{\text { Mundo }) \\
& \text { E. V }(7 \text { vsos. }) \ldots \text { Amada }(y \text { Mundo }) \\
& \text { E. VI }(6 \text { vsos. }) \ldots \text { Fusión de } A+P(y M)
\end{aligned}
$$

Desde la aparición de $P$ (E. II), $M$ está conectado con este término de la relación alternante, lo que no sucede siempre con respecto al término $A$ : en E. I, la mujer fue contemplada y alabada en sí misma, en su propia perfección, y a partir de entonces el texto fue desarrollando contrapuntísticamente la oposición Amada/Poeta; pero en E. V la Amada es vista ya con implicaciones cósmicas ("Tú estás de pie sobre la tierra, llena// de dientes y relámpagos"), es decir que desde este momento también $A$ se impregna de $M$ (pero con signo contrario al de $P$ : el Poeta se había descubierto carente y finalmente vencido por un universo inaprehensible y en constante desintegración, EE. II.III-IV; la Amada se yergue sobre ese universo, E. V). Es precisamente en ese instante cuando el ritmo alternante de contenidos $A / P$ cesa, para dar lugar a la compa. tibilidad temática de $\mathrm{E}$. VI, donde la mujer, vencedora del mundo, es por lo mismo la posibilidad de refugio salvador para el poeta amante. De ese modo, $M$ condiciona y da su sentido a la constelación temática del texto, y con ello a la construcción de contenidos a nivel interestró. fico. ${ }^{8}$

8 Esta relación triádica en que dos individualidades adquieren el sentido de su relación gracias a lo que las trasciende (acá, la inquietud por lo ontológico; en otras etapas de la poesia nerudiana, lo social o lo político-social), es una de las constantes en este autor. Lo que varía es el tipo de relación y su signo valorativo, de acuerdo con la tensión con que los vive el yo poético: unas veces es la mujer, como aquí; otras el amigo (García Lorca...), o el enemigo político (González Videla...), o el héroe histótico, o el anónimo. E. Rodríguez Monegal (El viajero inmóvil. Introducción a la obra de Pablo Neruda, Bs. Aires, 1966), estudia la relación Yo-Amada-Mundo sólo en etapas posteriores de su producción: en "Regresó la sirena" (de Las uvas y el viento), la ciudad de Varsovia y la mujer se trasmutan poéticamente, asi como en Los versos del Capitán el mapa del cuerpo femenino metaforiza el mapa de América. Pero en "Oda con un lamento" ya es la obsesión por el Fundamento (en el sentido 'metafísico' del término) lo que 
Pero además la 'duración' de cada tema alternante $A / P$ es fundamentalmente distinta, como el esquema de más arriba ha podido mostrar: la mujer necesita en cada aparición solamente una estrofa y nunca de entre las más extensas del poema; el amante se expande en tres grupos estróficos sucesivos, que se 'estiran' progresivamente (procedimiento que la tensión entre sintaxis y metro, según veremos, contribuye a destacar), y rompe siempre con todo molde métrico durante el desarrollo de cada agrupamiento, además. Los versos dedicados a la Amada están siempre medidos (en E. VI donde se funde el juego dialéctico $A / P$, son precisamente los versos de $P$ los que incluyen el único intento de ametricidad). Todo esto será desarrollado en su momento, pero es evidente la conclusión a que estas observaciones nos conducen: la Amada es aquí lo cabal, lo acabado en sí mismo y por lo tanto el lenguaje que la expresa tiende siempre a someterse a una ley de contención, a la medi. da; el Poeta, cuya relación con el universo y consigo mismo se da sobre la base de lo amorfo, de la desarticulación y del 'poeta-antena' (Alonso) que construye siempre sin terminar de construir, tiende a diluir la rigu. rosidad de toda forma y rebasa a cada momento sus propios moldes. Esta polarización entre contención y rechazo de toda ley de mensura, cuya relación con los contenidos estructurantes del texto acabamos de exponer, construye y da su sentido a la totalidad rítmica del poema.

\section{ESTROFA I:}

1. Oh niña entre las rosas, oh presión de palomas,

2. oh presidio de peces y rosales,

3. tu alma es una botella llena de sal sedienta

4. y una campana llena de uvas es tu piel.

Diríamos que este primer agrupamiento estrófico, que es precisamente la alabanza de la amada, se obstina por constituirse sobre la base de una gran nitidez rítmica - -en relación con lo que va a ser el resto del poema-, sólo muy levemente traicionada por la fluctuación entre verso alejandrino (vv. 1, 3, 4) y endecasílabo (v. 2). Pero se trata de un endecasilabo con acento en 6a. ("oh presidio de péces..."), en el que reconocemos dentro del verso largo, la misma célula rítmica heptasilábica

motiva el modo con que ese Yo experimenta la búsqueda del Tú: por el momento, ese Tú funciona como una especie de delirante canalización hacia lo individual de un ansia por la integración en la Totalidad, que no se logra aquí, sino en un momento privilegiado de la IIa. Residencia, los "Tres cantos materiales" (cf. J. Concha, "Interpretación de Residencia en la Tierra", en rev. Mapocho, T. I, No. 2, julio $1963,5.39$ ). 
que llena los hemistiquios de los otros tres versos. Desde ahora pues, se ha impuesto una dominante de siete sillabas con acento fijo en la penúltima, que va a reaparecer a lo largo del texto cada vez que éste busque atenerse al polo de la ley de medida.

Las unidades o subunidades métricas coinciden apretadamente con las sintácticas, con lo que se refuerzan mutuamente y contribuyen al efecto de orden constructivo: las exclamaciones anafóricas coincidentes con límite de hemistiquio o de verso (v. 1 , a y 1 , b y v. 2); las dos aseveraciones coordinadas separadas por la pausa versal (vv. 3 y 4 ). Estas coordinadas se corresponden perfectamente en su estructura sintáctica, y el ordenamiento en forma de quiasmo es un elemento más en esa correspondencia: "tu alma (SUJ.)/es (V. Cópula)/ una botella llena de sal sedienta (Predicativo)" frente a "una campana llena de uvas (Predicativo) / es (V. Cópula) / tu piel (SuJ.)"; además la construcción interna de cada predicativo es casi idéntica, a lo que debemos agregar la recurrencia léxica (posesivo "tu", indefinido "una", verbo "ser"; sobre todo, el adjetivo "Ilena" por su posición privilegiada, antes y después de la cesura respectivamente). En los hemistiquios con reiteración léxica $(3$, b y $4, a)$ el esquema acentual es además idéntico: $1--1-1-$.

La coordinación copulativa inicia a su vez un ritmo sintáctico bimem. bre que retornará varias veces en el texto; a nivel de contenidos se corresponde con una recurrencia (parcial), en donde el segundo miembro sirve de variación semántica a lo mentado en el primero: efecto de simetría ordenadora donde un tiempo del compás se cierra retomando el mismo recorrido que el anterior ( $\mathrm{cf}$. con otros momentos del poema: "cenicientos caballos y perros amarillos", E. III, 3; "desamparadas pasiones y desolados besos", E. IV, 2; "me miro en los espejos y en los vidrios", E. IV, 10, etc.) : o si no, la correspondencia semántica se da mediante la formulación antitética ("tú propagas los besos" = difundes apetencia de comunicación entrañable, "y matas las hormigas" = anulas la amenaza de lo oscuro e inaprehensible, E. V, 3; "ven con una man. zana y un caballo" = el principio femenino que es a la vez la incitación de lo erótico, y el principio masculino y a la vez la pasión en su mo. mento de culminación, E. VI, 3). En realidad, estos versos 3 y 4 de E. I combinan ambos procedimientos: sinonimia de frase (idea de plenitud colmada) y contraste (alma, v. 3 / cuerpo, v. 4).

Cabe señalar ahora de qué manera la estrofa destaca formalmente los dos momentos en que está estructurada, de acuerdo con dos modos 
diversos de acceder a la contemplación del ser amado: visión sintética de la mujer (vv. 1-2), visión analítica alma/cuerpo (vv. 3-4):

vv. 1 - 2: -anáfora exclamativa + unimembre exclamativa

-recurrencia fónico-semántica ante pausa métrica: "rosas" . . "rosales"

-recurrencias sonoras propias: aliteración de $P$ en posición métricamente equivalente, o casi (inmediata. mente antes de los dos acentos en 1, b y el primer tramo de v. 2: "presión de palomas $/ / \ldots$ presidio de peces"); de vibrantes ("entre...rosas ... presidio... rosales"); de tramos sonoros más vastos que el fonema y la sílaba ("pres.... pres....")

vv. 3-4:-correspondencia sintáctica en quiasmo (v. supra)

-recurrencias sonoras distintas de las del tramo anterior: aliteración de $l$ y $l l$ ("alma. . botella ...llena ... sal ...llena ... piel"), y de nasales $m$-m ("alma ...una ...llena... sedienta...una campana Ilena")

A distinta actitud del contemplador y amante, distinta organización del material rítmico-poético. (Lo notable es que, por otra parte, los contrastes netos a que dará lugar la marcha temática del texto y que hemos adelantado más atriba, no excluyen procedimientos de transición que crean, por encima de la oposición de contenidos, una atmósfera de continuidad realizada en otro nivel: aqui, el paso de esta estrofa a la siguiente, que marca la oposición $A / P$, queda sin embargo atenuada por la continuidad aliterativa de nasales, con leve variación: de $m-n$ en $E$. I se deslizará a $n-\tilde{n}$ en E. II. Procedimientos semejantes, aunque a cargo de niveles distintos de expresión, hallaremos en otros momentos del texto donde vuelva a cumplirse una nueva alternancia temática. De ese modo, la síntesis $A+P$ que se cumplirá francamente sólo en la estrofa final del poema, queda como remotamente preparada por estos procedimientos de enlace que comentamos.)

A su vez, dentro de E. I la partición en dos momentos no impide el empleo de técnicas de unificación estrófica, exigidas por el referente común que ha agrupado en un haz estos cuatro versos (la mujer) y por el tono asumido (de alabanza), y ellas están dadas ante todo en el plano de la simbología aquí adoptada y su modo de distribución. Nótese cómo a cada subunidad sintáctico-métrica, corresponde siempre una imagen cu. 
yas dos notas comunes son siempre: a) la superabundancia de una plenitud -el parcial contrasentido de mi expresión es intencional, ya que lo pleno reclama el calificativo de lo perfecto más que de lo rebasante, pero la efervescencia expresionista con que están sentidas estas realidades así lo exige-; b) su autosuficiencia, expresada por la imagen del recipiente que contiene y preserva una totalidad (campana, botella llena, presidio de peces...), o del enmarcamiento, que cumple parecida función (las rosas que rodean a la muchacha y centran su presencia), o de la concentración suprema (presión de palomas). Así, los símbolos han contribuido a ajustar el hilo unificador de E. I por el procedimiento de la variación reiterativa sobre una misma intuición básica. En estrecha relación con ellos, además, está la recurrencia morfológica de los plura. les ("rosas", "palomas", "peces y rosales"... "uvas") en tres de esos cuatro versos, y en posición equivalente pues siempre cierran complementos encabezados por preposición.

ESTROFA II:

1. Por desgracia no tengo para darte sino uñas

2. o pestañas, o pianos derretidos,

3. o sueños que salen de mi corazón a borbotones,

4. polvorientos sueños que corren como jinetes negros,

5. sueños llenos de velocidades y desgracias.

Las estrofas dedicadas a $P$ empiezan gradualmente a prolongar su extensión, en un 'estiramiento' no sólo métrico sino también sintáctico. Pero sólo gradualmente (tendremos que aguardar hasta las dos siguientes para que eso llegue a su culminación) : lo mismo con respecto a la disposición interna de versos métricos y amétricos, pues en w. 1.2 todavía no nos apartamos de la fluctuación alejandrino/ endecasílabo en 6a., en la que no sólo se mantiene la dominante heptasilábica, sino que en el segundo la pausa interior sintáctica propone un nuevo molde heptasílabo que se superpone al meramente métrico:

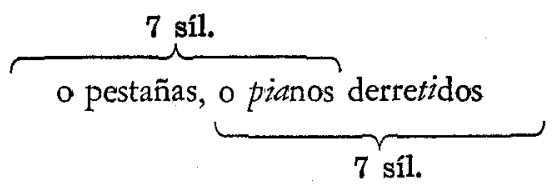

El esquema en dos pies del primer heptasílabo ( $-\ldots, \ldots,-1$, : "o pestañas, o pianos") es el mismo que armó el alejandrino anterior, 
en cada una de sus mitades ("Por desgracia no tengo / para darte sino uñas").

Pero enseguida (vv. 3 ss.) toda contención es rebasada, y aunque la última línea se repliega a las 14 sílabas ("sueños llenos de velocidades y desgracias") en una especie de extenuación, no llega a acogerse al esquema alejandrino con cesura ni respeta molde acentual alguno: es todavía un verso amétrico. Pero el inicio de la estrofa sí: otto modo (como el de aliteración de nasales, que acá inunda todos los versos) ${ }^{9}$ de no desprenderse demasiado abruptamente de las formas conectadas con el tema contrastante anterior, tema todavía aludido en v. 1 , donde se hace referencia a la relación entre amante y amada ("por desgracia no tengo para darte..."). No bien aquél se ha adentrado en su propia intimidad y en su modo informe y desbordante de experimentar lo caótico, entonces la sintaxis, la unidad versal o ambos, se desbordan también. Entonces la estructura sintáctica se vuelve redundante, al avanzar, como observó Alonso, por adiciones cuyo dibujo total no se prevé desde el principio porque obedece a oleadas emocionales que se desatan sin terminar de configurar una forma definida. Y ello, mediante dos procedimientos, que deslindan los dos tramos estróficos: w. 1.2 y arranque del 3 , por el polisíndenton disyuntivo o...o..o y su consiguiente efecto de encadenamiento abierto, que crece por mera acumulación; y enganchado al último miembro en una prolongación imprevista y desmesurada que abarca vv. 3-4-5, la coordinación intensificativa con "sueños" como núcleo-pivote, que se reitera a sí mismo pero sin paralelismo riguroso y en variadas posiciones con respecto a los limites versales, sin pautar necesariamente sus goznes:

\author{
o sueños que salen... \\ polvorientos sueños que corren... \\ sueños llenos...
}

Fueron estos miembros sintácticos así concebidos los que impusieron la no controlada extensión de las unidades versales, su no-medida. $Y$ en cuanto a la diferencia de recursos rítmico-sintácticos utilizados en las dos partes de esta estrofa, ella se corresponde con un cambio en la orientación de los contenidos: a la enumeración caótica de vv. 1.2 (cuyos

$9 \mathrm{La}$ insistencia en las correspondencias meramente fónicas, cuya base irracional se conecta con las modalidades superrealistas de este poema, según vio Alonso, se extiende en Neruda más allá de los juegos aliterativos y abarca el balbuceo léxico del tipc "Ay cuándo//ay cuándo/y cuảndo//ay cuándo me encontré contigo", leitmotiv dirigido a la tierra chilena en otro poema del autor. 
elementos insinúan a su vez un ritmo semántico en su común alusión a lo desintegrado: por atomización, en el fragmentarismo de "uñas" y "pestañas" - que además aliteran entre sí; por degradación de una plenitud en "pianos derretidos"), sigue en cambio la referencia al propio sentimiento del poeta, transido por la amenaza de lo funesto y en descontrolado aluvión (vv. 3 a 5: sueños polvorientos, lo negro, las desgracias, $/ \mathrm{y}$ borbotones de sueños, velocidades, jinetes).

ESTROFA III:

1. Sólo puedo quererte con besos y amapolas,

2. con guirnaldas mojadas por la lluvia,

3. mirando cenicientos caballos y perros amarillos.

4. Sólo puedo quererte con olas a la espalda,

5. entre vagos golpes de azufre y aguas ensimismadas,

6. nadando en contra de los cementerios que corren en ciertos ríos

7. con pasto mojado creciendo sobre las tristes tumbas de yeso,

8. nadando a través de corazones sumergidos

9. y pálidas planillas de niños insepultos.

Las tres estrofas del texto alusivas al poeta amante y su modo de experimentar lo existente, imponen un movimiento rítmico propio que es el que vimos ya en la anterior: tendencia inicial a la medida métrica, luego crecimiento por expansión no controlada, y finalmente repliegue por extenuación. Pero no se calcan una sobre la otra: aquí en E. III hay un doble asedio, un doble intento por retomar el esquema, que finalmente se cumple pero gracias a un nuevo estiramiento estrófico que intensifica el efecto de marejada emocional no racionalmente controlada. La sintaxis contribuye como siempre a ese efecto: el v. 4 reanuda la estructura métrica (alejandrino) y oracional que se planteó en v. 1: "Sólo puedo quererte" + circunstanciales preposicionales + circunstancial con gerundio; pero la segunda vez en notable prolongación hacia el polo de la desmesura, multiplicando complementos o injertando unos dentro de otros, introduciendo coordinaciones intensificativas (el gerundio "nadando" con su insistencia fónica y posicional en principio de vv. 6 y 8 , haciendo eco al "mirando" de comienzo de v. 3); compárense los dos tramos estróficos y su desproporción a favor del segundo:

Sólo puedo quererte con besos y amapolas...
Sólo puedo quererte con olas a la espalda, 
con guirnaldas... mirando... entre vagos golpes. .

y aguas...

nadando en contra...

con pasto mojado. .

nadando a través de corazones...

y pálidas planillas...

Los vv. 6-7 llevan al clímax esa desproporción, tanto en crecimiento silábico como porque el núcleo sintáctico "nadando" soporta un complemento que incluye una larga subordinada _."que corren..."- con, a su vez, un complemento preposicional que abarca todo el v. 7 , éste por su parte articulado en complementos que incluyen otros complementos: "con pasto mojado creciendo sobre las tristes tumbas de yeso". Hacia el final, el v. 8 decrece a 14 sílabas - pero no todavía con ritmo alejandrino-, y el último vuelve al esquema de $7+7$ cerrando así el ciclo, y reforzando esa vuelta a la forma por una nueva combinación aliterativa $p$-l, que tiende a la simetría porque aparece con vocal intermedia en ambos cabos de verso y sin ella hacia el centro: "y pálidas planillas/ de niños insepultos". ${ }^{10}$ La marejada emocional se ha aquietado, disecándose casi en esa imagen del último verso y su geometría métrica. En el resto, campeó la aliteración de nasales $n, m$ que venía obrando desde antes y dominará también, en la estrofa siguiente, apoyando fónicamente la cohesión te. mática.

Esa cohesión se da también mediante la recurrencia de un tipo de sintagmas que apareció aisladamente en $\mathbb{E}$. III, cuya frecuencia desde ahora se intensifica y cuya estructura semántica (y aun semántico-morfológica en los ejemplos de la segunda columna) nos remite al sentido del tema del Poeta y puesto que le es exclusiva, lo caracteriza; reaparecerán estos sintagmas cuando $P$ reaparezca en la última estrofa del texto; véase:

$$
\text { pianos derretidos (II, 2) }
$$

caballos cenicientos (III, 3) guirnaldas mojadas (III, 2) perros amarillos (III, 3) aguas ensimismadas (III, 5)

10 Apurando un análisis más minucioso al modo de $\mathrm{K}$. Burke ("On musicality in verse", en su The Pbilosopby of Literary Form, N. York, 1957, 296-304), es posible explotar mejor el estudio de las correspondencias fónicas de este verso, como de muchos otros del poema. Por ejemplo: $p l$ alitera parcialmente con $l l$, afín de $l$, y $l l$ con la otra palatal $\sqrt{n}$ en posición simétrica pues siguen a la $i$ acentuada que está a ambos lados de la cesura: "...planillas//de níños...", y además cada $\dot{i}$ está precedida por $n$ (nill, niñ), lo que refuerza más la reiteración del grupo acentual - - a que pertenecen; la $-s$ de los plurales alitera a lo largo de todo el verso, tras a- en primer hemistiquio, tras o- en segundo; 
niños insepultos (III, 9)

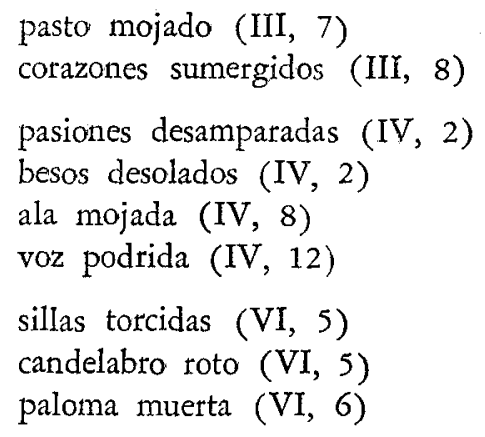

En todos ellos, un sustantivo sentido como 'noble' queda degradado en su valoración por la adjetivación negativa, que a menudo estáy dada mediante un participio, cuyo valor aspectual de proceso cumplido (acción desgastada) acentúa la carga de temporalidad que todo lo consume desintegrando el vigor de lo existente. Procedimiento aprendido con toda evidencia en Quevedo.

Pero aparte de esto, la estrofa que comentamos construye recurrencias rítmicas propias, sobre la base de nuevas anáforas léxicas ("con. . .con", "nadando..."), de frase ("sólo puedo quererte..."), y esa especie de anáfora morfológica constituida por la cadena de gerundios "mirando... nadando... nadando". En todos los casos se deben a 'enganches' sintáctico-semánticos con lo que se ha acabado de decir y al terminarlo de decir se lo siente como no acabado, lo que obliga a reanudar el esquema de frase para desarrollar un nuevo tramo, siempre en la línea expresiva do una sintaxis aditiva, de insistencia, de dibujo que se va completando con el empujón de intuiciones no acabadas de configurar. Los últimos versos (vv. 6-9) se arman sobre la coordinación intensificativa del gerundio de 'nadar', que da fisonomía propia a ese subgrupo para corresponder al contenido, también propio, que el subgrupo expresa (rebeldía del poeta, que 'nada en contra, a través' de la invasión de muertes que impregna la vida, para vencerla por el canto).

ESTROFA IV:

1. Hay mucha muerte, muchos acontecimientos funerarios

2. en mis desamparadas pasiones y desolados besos,

3. hay el agua que cae en mi cabeza,

4. mientras crece mi pelo,

y en aquél es claramente perceptible la ondulación vocálica á-i-a-í-a, con corrimiento acentual de una vocal a otra. 
5. un agua como el tiempo, un agua negra desencadenada,

6. con una voz nocturna, con un grito

7. de pájato en la lluvia, con una interminable

8. sombra de ala mojada que protege mis huesos:

9. mientras me visto, mientras

10. interminablemente me miro en los espejos y en los vidrios,

11. oigo que alguien me sigue llamándome a sollozos

12. con una triste voz podrida por el tiempo.

Es el grupo más extenso del poema y el momento en que los crecimientos por adición y enganche llegan a su paroxismo. En cuanto a lo métrico, un mero recuento de las apariciones del molde heptasílabo nos llevará a conclusiones falsas si no las vinculamos con sus modos de distribución y con el ritmo sintáctico. Lo que sucede en realidad en E. IV es una especie de deslabazamiento del esquema rítmico que se planteó en EE. II y. III: la marea estrófica busca ese esquema y lo traiciona en el mismo momento en que lo busca. Así, lo que empezamos a leer en v. 1 como un primer hemistiquio heptasílabo (esperable por tratarse de iniciación estrófica, que retoma el esquema inicial y quedar ya impuesto éste al final del grupo anterior), se disuelve en un encabalgamiento, que se impone aún más sobre la posible cesura por el destaque anafórico ("Hay mucba muerte, mucbos/..."), y luego queda frustrada su reaparición al romperse el segundo hemistiquio por estiramiento silábico (".../acon. tecimientos funerarios": 10 sílabas); el paralelismo sintáctico, la sinonimia de frase y el juego anafórico hacen especialmente perceptible el desajuste de estos dos momentos del verso con el molde métrico que contribuyen a romper. Algo parecido sucede, pero en un orden inverso, con v. 2: "en mis desamparadas pasiones / y desolados besos" incluye dos estructuras sintácticas paralelas - pero sólo la segunda constituye un heptasílabo cabal-, cuyas correspondencias quedan reforzadas por otras de orden morfológico (complementos participiales, en similicadencia) y la $s$ aliterada también paralelísticamente; lo cual contribuye a destacar el desequilibrio métrico, al no acompañar éste esas correspondencias (el primer 'hemistiquio' es de 10 sílabas, y éstas a su vez, sin ninguna relación acentual con las 10 sílabas del estiramiento de v. 1).

En adelante la estrofa va a crecer mediante las acumulaciones de sintaxis aditiva que conocemos, pero creando por otra parte recurrencias propias por el nuevo tipo de vocabulario anafórico empleado ("hay... hay"; "mientras...mientras"; "un agua... .un agua"), y distinto tipo de esquema sintáctico (impersonales con 'haber', con su sugerencia de indeterminación inquietante; subordinadas temporales, expresivas del fluir 
que no se detiene ni al ejercer los actos más estéticos: 'mirarse en los espejos y en los vidrios'): lo cual mantiene, como diría Alonso, el 'tono conductor' de cada pliegue estrófico, y lo mantiene siempre de un modo jadeante; esa 'tónica' a veces enhebra tramos distintos, superponiéndose a los otros más localizados: véase el "interminable", que cierra el v. 7 , antes de terminar el primer largo período gramatical, y el "interminable (mente)" que abte el v. 10, ya en otra unidad sintáctica y en posición gramatical y métrica diversa, pues se apartan del juego anafórico (y esto contribuye al efecto de impetuoso desorden). Pero el jadeo emocional no sólo se hace aquí más prolongado e insistente sino que adquiere una intensidad inédita, pues a poco de someterse el verso a los moldes métri$\cos$ conocidos, una cadena de encabalgamientos —anafóricos ademáscontradice casi constantemente la metricidad, y ésta a su vez mezcla azarosamente los patrones adoptados (no sólo, 7, ó $7+7$, u 11 con acento en 6a., sino varias veces un estiramiento de $7+11$; y de esos endecasílabos, alguno con acento sólo en $4 a$., con lo que se quiebra el impulso heptasílabo básico). Esquematizando a partir de cuando se retorna a la medida silábica:

$$
\begin{aligned}
& \text { v. } 3 \ldots 11 \text { síl. (ac. en 6a.) } \\
& \text { v. } 4 \ldots 7 \text { sil. } \\
& \text { v. } 6 \ldots 11 \text { síl. (ac. en 6a.), que encabalga con } \\
& \text { v. } 7 \ldots 77+7 \text {, que encabalga con } \\
& \text { v. } 8 \ldots 7+7 \text {, que encabalga con } \\
& \text { v. } 9 \ldots 7 \text { síl., que encabalga con } \\
& \text { v. } 10 \ldots 7+11 \text { (ac. en 6a.) } \\
& \text { v. } 11 \ldots 7+7
\end{aligned}
$$

El v. 12 remata la estrofa con un alejandrino 'descoyuntado', que suspende la cesura debido a un primer hemistiquio con final agudo y frase encabalgada ("con una triste voz — podrida..."), con lo que la estructura métrica diluye un tanto su geometrismo. Pero igualmente se da el efecto final de repliegue anticlimático, mediante la reducción métrica de este verso y el anterior. Además el v. 12 llega a imponer sobre la textura fónica de nasales que venía desarrollándose, un juego aliterativo distinto - como sucedió al final de E. III-: esta nueva aliteración se da a partir del grupo tri, que deriva a $d r i$ en el 20 . hemistiquio, la primera de cuyas consonantes alitera dentro de la misma palabra ("tris. te... podrida"); la $t$ oclusiva sorda deriva a oclusiva labial $p$ y produce los grupos con vocal $o$ intermedia po.r, que se reitera en disminución en ese 2o. hemistiquio: 
con una triste voz - podrida por el tiempo.

La sonoridad relativamente áspera de los grupos con consonante líquida $r$, en adecuada relación con el contenido, y la nueva textura fónica que se impone a la otra, valoriza por contraste este final estrófico y contribuye a imponerlo como final.

Pero en casi todo el resto de la estrofa, según lo que ya comentamos, todo el movimiento rítmico consistió, o en una dispersión azarosa de los moldes métricos, que sin embargo eran respetados como tales hasta en los casos de estiramiento, vv. 5 y 10 (una especie de irregularidad a base de regularidades); o en el desajuste sistemático de ritmo sintáctico y ritmo métrico mediante la recurrencia de encabalgamientos (recurrencia que como tal, configura un ritmo propio: regularidad a base de irregularidades, de rupturas). De esa manera la polarización entre forma y no-forma lleva en esta estrofa climática su tensión al máximo, pues superando el juego de alternancias, se ejerce al mismo tiempo sobre el mismo material expresivo. Los versos finales nos devuelven al apaciguamiento de siempre, y esta vez nos preparan - procedimiento de transición- para el ordenamiento relativo de E. V, dedicada a la Amada.

ESTROFA v:

1. Tú estás de pie sobre la tierra, llena

2. de dientes y relámpagos.

3. Tú propagas los besos y matas las hormigas.

4. Tú lloras de salud, de cebolla, de abeja

5. de abecedario ardiendo.

6. Tú eres como una espada azul y verde

7. y ondulas al tocarte, como un río.

Ahora todos los versos están medidos, según lo anticipado al comienzo de nuestro análisis, y ninguno rebasa las 14 sílabas (el orden suce. sivo es el siguiente: $11 ; 7$; dos alejandrinos; 7,$11 ; 11$ ). Incluso el v. 3 distribuye ambos hemistiquios en correspondencia con la coordinación sintáctica, con la y como eje junto a la cesura; vv. 6-7 coinciden también en sus límites, con límite de coordinación; v. 7 enfatiza, con la pausa sintáctica tras 7a. sílaba, la dominante métrica del texto ("y ondulas al tocarte, (..."). Sin embargo, ya dijimos que la oposición entre los temas $A / P$ no impide superposiciones y técnicas de transición, lo cual se advierte aquí sobre todo en vv. $1-2$, cuya metricidad recubre un conte- 
nido hecho de imágenes en visión caótica (la risa de la amada como invasión de relámpagos y dientes): de tal modo el sentimiento del amante contamina, interfiere en la intuición de ordenada plenitud que brota de la mujer, lo que queda también expresado en el desencuentro del encabalgamiento. Este encabalgamiento realiza además un nuevo desajuste entre forma y no-forma, al escurrir, tras la sucesión métrica endecasílabo//heptasilabo, una sugerencia de dos eneasílabos superpuestos en ese adelantar la pausa sintáctica con respecto a la pausa versal; es el juego de esos dos ordenamientos distintos lo que produce, con el encabagal. miento, la contradicción entre las formas (nótese cómo pugna por imponerse el esquema eneasílabo, mediante la acentuación repetida en $1 a$. 4a. y 8a.):

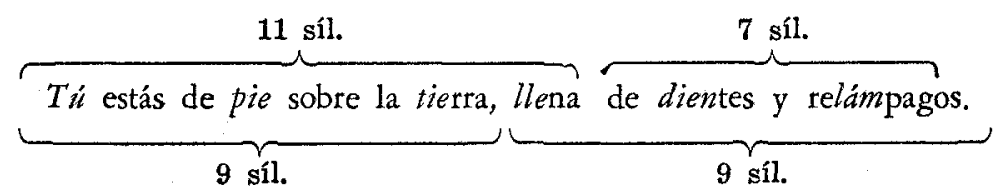

El "Tü" anafórico, seguido inmediatamente del verbo, contribuye a sostener la unidad del grupo estrófico. Otros efectos en cambio, se reducen a la extensión de cada oración gramatical, cuyo matiz de contenido apoyan, al mantener una coherencia fónica propia: en vv. 1.2 las aes acentuadas enmarcan cuatro acentos en ie (o lle, de sonoridad parecida: "...estás de pie sobre la tierra, llena// de dientes y relámpagos"); en v. $3, a$ seguida de a en ambos verbos refuerza el paralelismo de la coordinación ("propagas los besos/y matas las hormigas"). En vv. 4.5 se trenzan 11.1, b-d, s, además de la preposición "de" insistentemente anafórica (pero en tramos muy breves, de modo que el asíndeton que acumula por adición estos complementos se somete, como toda la estrofa, a la ley de la contención: "de salud, de cebolla, de abeja,// de abecedario ardiendo"). El paralelismo métrico de vv. 6-7 (dos endecasílabos en 6a.) y su correspondencia con las subunidades sintácticas en coordinación, llevan a culminación la tendencia ordenadora de $\mathrm{E}$. V; y su contenido deriva hacia el toque sensual, que nos prepara para la invitación erótica de E. VI (transición).

EstrofA VI:

1. Ven a mi alma vestida de blanco, con un ramo

2. de ensangrentadas rosas y copas de cenizas, 
3. ven con una manzana y un caballo,

4. porque allí hay una sala oscura y un candelabro roto,

5. unas sillas torcidas que esperan el invierno,

6. y una paloma muerta, con un número.

La fusión temática (y la de ambas individualidades en la unión de amor) se difunde a partir del eje sintáctico de toda la estrofa, que es el imperativo verbal en reiteración anafórica. Como era de esperar, orden y no-orden alternan o se superponen en esta síntesis final: el v. 1 diluye el alejandrino con un doble encabalgamiento, entre hemistiquios ("vestida - de blanco") y entre versos ("un ramo//de ensangrentadas rosas..."); el v. 2 nos devuelve al esquema $7+7$ con cesura y correspondencia sintáctica en forma de quiasmo, con la conjunción como eje (. . compl. + sust./conj., sust. + compl.); el v. 3 es un endecasílabo en 6a., pero el 4 crece en su primer tramo por estiramiento ("porque allí hay una sala oscura") y sólo preserva un segundo tramo heptasílabo ("y un candelabro roto"); el v. 5 retorna al alejandrino ortodoxo; y en cuanto al verso final

$$
\text { y una paloma muerta, con un número }
$$

en su primer tramo mantiene el ritmo heptasílabo del anterior, destacado por la pausa sintáctica, pero luego se quiebra reduciéndose a endecasí. labo, y su efecto de remate seco se corresponde con el contenido, alusivo a la cifra que como toda cifra mata la vida. La aliteración de nasales, que había dominado en el tema de $P$, reaparece en v. 6 y lo destaca. El símbolo de la paloma, que abrió el poema junto con la imagen de la muchacha, ahora lo cierra vinculado con el amante, y por lo mismo degradado en su valoración por el participio que lo acompaña.

Esta "Oda con un lamento" anuncia desde su título la fisura que atraviesa la intuición básica del poema y da sentido a su ritmo: esa fisura ha consistido en la imposibilidad del poeta de hallar descanso en la confianza de un Orden cósmico, y es la mujer la que aparece aquí como única oportunidad para transferir, en su alegria y plenitud vitales, la búsqueda de una Forma constantemente elusiva.

Nicolás BratosEvich

Universidad Nacional de Rosario, Argentiva 
